\title{
P 081 THE ROLE OF INTERCULTURAL MEDIATION IN PROVIDING PALLIATIVE CARE IN A MULTICULTURAL SOCIETY
}

Bart Van den Eynden, ${ }^{1,2,3}$ Joke Scheers, ${ }^{3}$ Hans Verrept, ${ }_{1}^{4}$ Monique Elseviers ${ }^{3}$. ${ }^{1}$ Department Primary and Interdisciplinary Health Care, University of Antwerp, Antwerp, Belgium; ${ }^{2}$ Centre for Palliative Care, GZA Hospital, Antwerp, Belgium; ${ }^{3}$ Department Nursing And Midwifery Sciences, University of Antwerp, Antwerp, Belgium; ${ }^{4}$ Ministry of Health Care and Social Affairs, Federal Government, Brussel, Belgium

10.1136/bmjspcare-2014-000654.122

Introduction Ill persons from ethnical minorities are not cared for optimally in our healthcare system. Intercultural mediation aims to improve the accessibility and the quality of care for ethnical minorities. Due to the aging of the first generation of migrants, more and more migrants in Flanders will face an growing need for palliative care. Migrants elderly and palliative services are still rather unknown to each other. So it is not unthinkable that the intercultural mediator can play a significant role when in the future undoubtedly the number of migrant patients with palliative care needs will increase. While in the past interventions of intercultural mediators occurred rather on general wards, they now more often face palliative care.

Research question What could be the role of intercultural mediation in providing palliative care in a multicultural society?

Research Method This study used a qualitative descriptive method from a phenomenological research perspective where for the thematic analysis the coding paradigm of grounded theory was used.

Results Although a palliative care process must always be considered as an individual process, there are nevertheless many cultural differences. Both intercultural mediators and palliative care providers have less experience in guiding and supporting an intercultural palliative care process. The cooperation that currently exists, is considered as positive, although there are still many points waiting for improvement.

Conclusion The framework supporting intercultural mediators in guiding a palliative care process, is currently inadequate. This aspect should be paid for more attention in the near future. 